\title{
Diagnostic challenge and management of intraosseous mandibular hemangiomas: a case report and literature review
}

\author{
Maria Isabel Sánchez Jorge ${ }^{1}$, Jorge Cortés-Bretón Brinkmann², \\ Aranzazu González Corchón ${ }^{1,3}$, Rosa Acevedo Ocaña ${ }^{1}$ \\ ${ }^{\prime}$ Department of Oral Surgery and Oral Implantology, Faculty of Dentistry, University Alfonso X el Sabio, \\ ${ }^{2}$ Department of Dental Clinical Specialties, Faculty of Dentistry, Complutense University of Madrid, \\ ${ }^{3}$ Department of Oral and Maxillofacial Surgery, Hospital Clinico San Carlos, Madrid, Spain
}

\begin{abstract}
J Korean Assoc Oral Maxillofac Surg 2021;47:321-326)
Hemangioma is a benign tumor characterized by the proliferation of blood vessels. Although it often appears in soft tissues, its occurrence in bone tissue, particularly the mandible, is extremely rare. A 32-year-old female sought attention at the dental clinic complaining of a painless swelling in the posterior region of the left side of the mandible. A panoramic radiograph and computed axial tomography scan were taken, showing honeycomb and sunburst images, respectively, in the affected area. The patient underwent a biopsy, which led to the diagnosis of intraosseous hemangioma. Having assessed the characteristics of the lesion, it was decided to perform complete excision including safety margins, followed by an iliac crest bone graft to reconstruct the mandible. Awareness of the possible clinical and radiographic presentations of intraosseous hemangioma is considered important, as non-diagnosis could have severe consequences given its possible relation to dental structures.
\end{abstract}

Key words: Hemangioma, Bone, Mandible, Tumors

[paper submitted 2019. 9. 19 / revised 2019. 12. 2 / accepted 2019. 12. 9]

\section{Introduction}

Intraosseous hemangioma is a benign tumor of endothelial origin that represents only $0.5 \%-1 \%$ of all benign bone tumors and is characterized by the proliferation of blood vessels ${ }^{1}$.

Although hemangiomas are relatively frequent in soft tissues, their occurrence in bone tissue is quite rare and usually located in the spinal column or skull ${ }^{1,2}$.

Hemangioma may present at any age but is more frequent in adults between the second and fifth decades of life and, according to most research, has a clear predilection for females ${ }^{1-6}$.

\footnotetext{
Jorge Cortés-Bretón Brinkmann

Department of Dental Clinical Specialties, Faculty of Dentistry, Complutense University of Madrid, Pza Ramon y Cajal s/n, 28040 Madrid, Spain

TEL: +34-679295144

E-mail: brinkmann55@hotmail.com

ORCID: https://orcid.org/0000-0003-1701-8867
}

(c) This is an open-access article distributed under the terms of the Creative Commons Attribution Non-Commercial License (http://creativecommons.org/ licenses/by-nc/4.0/), which permits unrestricted non-commercial use, distribution, and reproduction in any medium, provided the original work is properly cited.

Copyright (C) 2021 The Korean Association of Oral and Maxillofacial Surgeons.
Diagnosis of this tumor is very complicated, as it is generally asymptomatic until it reaches a certain size and the patient starts to notice a slow-growing swelling, which may be accompanied by occasional pain, speech difficulties, or esthetic deformity ${ }^{2}$.

Its radiographic appearance is non-specific, making diagnosis even more difficult. It can appear as a unilocular or multilocular radiolucency, reticular pattern, honeycomb-like pattern, sunburst-like image, or as a set of vertical striations similar to the bars of a prison cell; it may even appear as a radiopaque area ${ }^{1-3,7,8}$.

Given its low incidence and non-specific clinical and radiographic forms of presentation, intraosseous hemangioma constitutes a real diagnostic challenge.

\section{Case Report}

A female patient aged 32 years came to the clinic because of a swelling of hard consistency in the left hemimandible. She reported first noticing the lump approximately a year previously.

Upon exploration, an increased volume in the vestibular 
area adjacent to teeth \#35, \#36, and \#37 was observed, which was hard but painless on palpation, without mucosal alteration, and practically indiscernible in extraoral examination. (Fig. 1) No dental mobility or pain on percussion were observed.

A panoramic radiograph was taken, which showed a reticular pattern with a honeycomb appearance in the region of the swelling.(Fig. 2) This was compared with an earlier radiograph

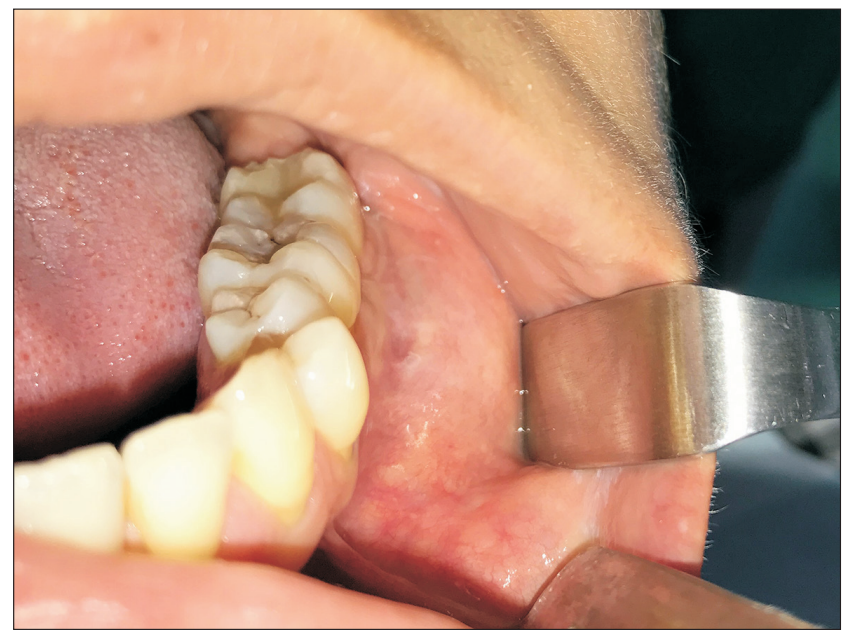

Fig. 1. Intraoral image showing increased volume in the vestibular area adjacent to teeth \#35-\#37.

Maria Isabel Sánchez Jorge et al: Diagnostic challenge and management of intraosseous mandibular hemangiomas: a case report and literature review. J Korean Assoc Oral Maxillofac Surg 2021 taken two years earlier, in which the lesion went unnoticed, as it was not yet clinically present. Then, a computed tomography (CT) scan was captured, which provided a sunburst-like image. The lesion measured approximately $30 \mathrm{~mm} \times 25 \mathrm{~mm}$, which did not affect the lingual cortical bone plate but did affect vestibular cortical bone, presenting reactive bone spicules.(Fig. 3)

It was decided to perform an intrabony incisional biopsy to obtain a definitive diagnosis, applying appropriate safety measures to avoid hemorrhage. Before this biopsy surgery, magnetic resonance imaging (MRI) and angiography were

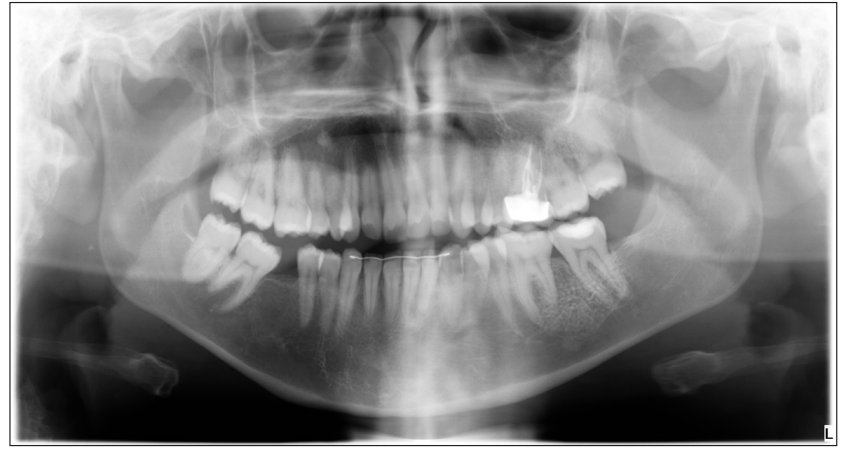

Fig. 2. Panoramic radiograph: honeycomb pattern in the third quadrant.

Maria Isabel Sánchez Jorge et al: Diagnostic challenge and management of intraosseous mandibular hemangiomas: a case report and literature review. J Korean Assoc Oral Maxillofac Surg 2021
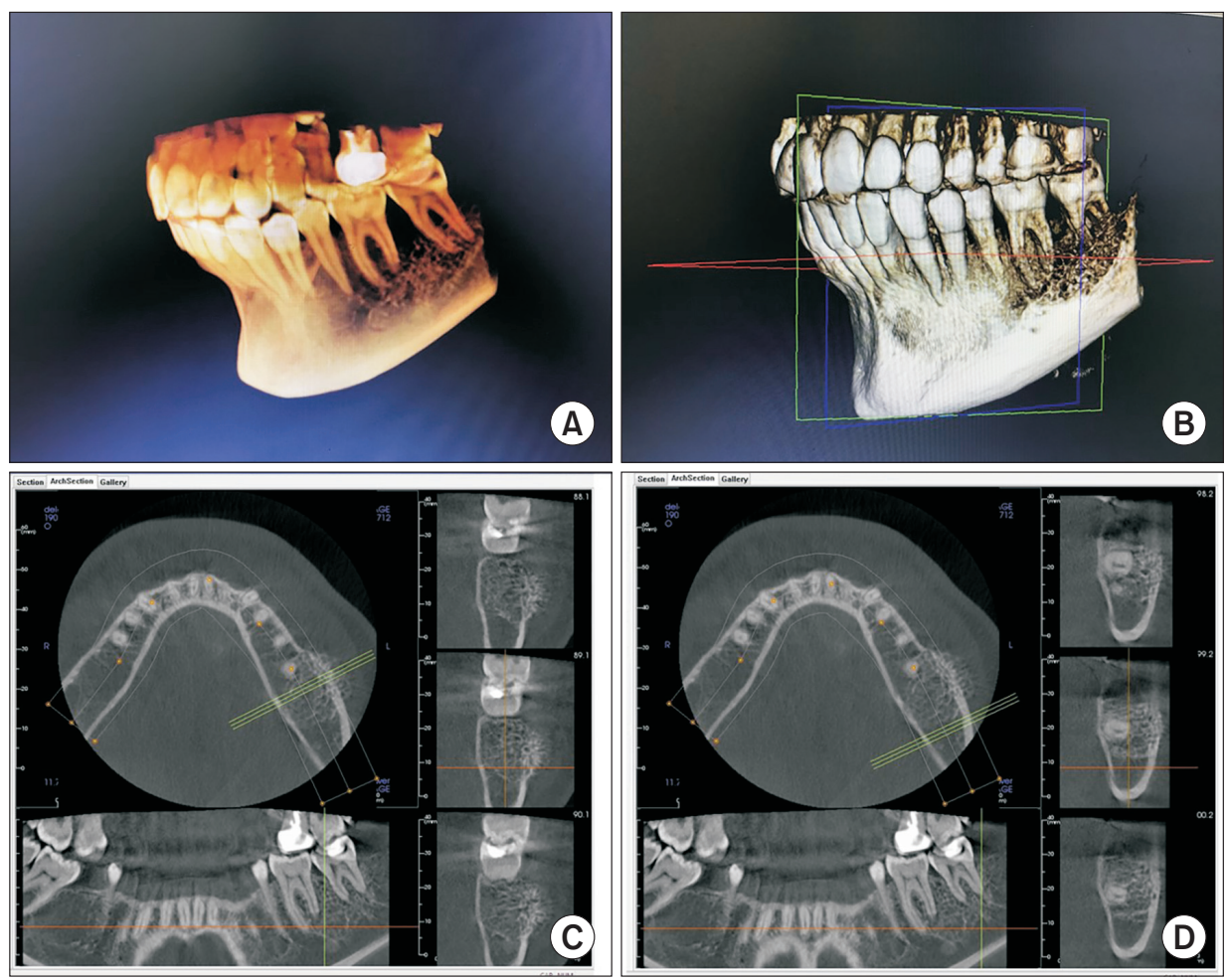

Fig. 3. Computed tomography scan A, B. Three-dimensional reconstruction of the mandible. C, D. Sunburst image; note the presence of reactive bone spicules.

Maria Isabel Sánchez Jorge et al: Diagnostic challenge and management of intraosseous mandibular hemangiomas: a case report and literature review. $J$ Korean Assoc Oral Maxillofac Surg 2021 
performed to determine the extent of tumor growth into the soft tissue, assess the blood flow, and identify nutrient vessels.(Fig. 4)

Anatomopathological analysis revealed the presence of bone trabeculae and spicules, and between them, numerous vascular structures were identified with muscular walls and dilated spaces separated from one another by fibrous tissue. No signs of malignancy were observed. The diagnosis was an intraosseous cavernous hemangioma of the mandible.(Fig. 5)

Intraoperatively, the lesion presented a moth-eaten appearance and was filled with vascular soft tissue.(Fig. 6) Given the patient's age, the treatment of choice was to remove the hemangioma with safety margins, followed by an iliac bone

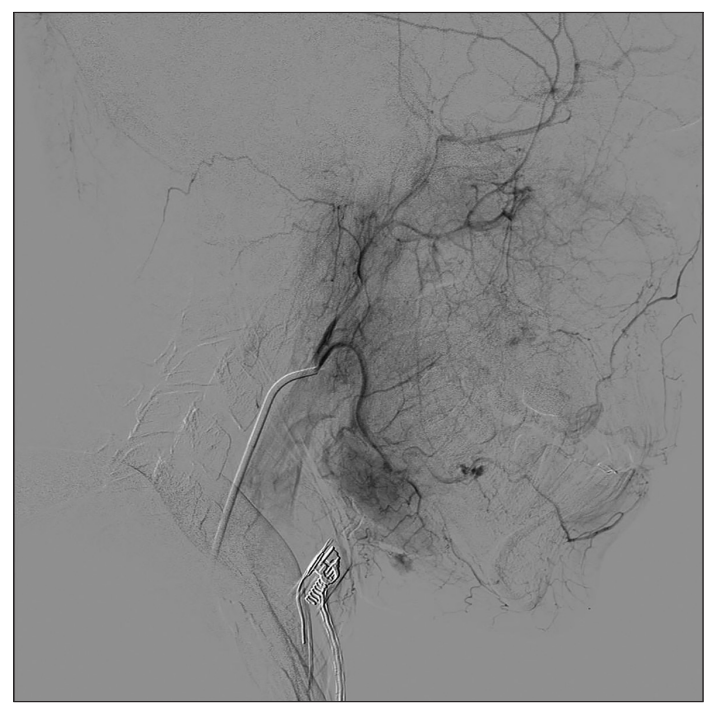

Fig. 4. Angiography showing the main vessels supplying the intraosseous hemangioma.

Maria Isabel Sánchez Jorge et al: Diagnostic challenge and management of intraosseous mandibular hemangiomas: a case report and literature review. J Korean Assoc Oral Maxillofac Surg 2021 graft to reconstruct the mandible. After surgery, the patient reported anesthesia of the lower-left dental nerve, of which she had been warned previously.

A radiograph taken one year after surgery showed no signs of relapse.(Fig. 7) The anesthesia of the lower-left dental nerve persists, and the patient is currently scheduled to receive dental implants.

\section{Discussion}

Hemangiomas are benign vascular neoplasias characterized by an abnormal proliferation of blood vessels. They can occur in any vascularized tissue, including skin, subcutaneous tissue, muscle, and bone; intraosseous hemangiomas represent only $1 \%$ of all hemangiomas ${ }^{2,9}$. When they are located in bone tissue, they generally appear in the spinal column or

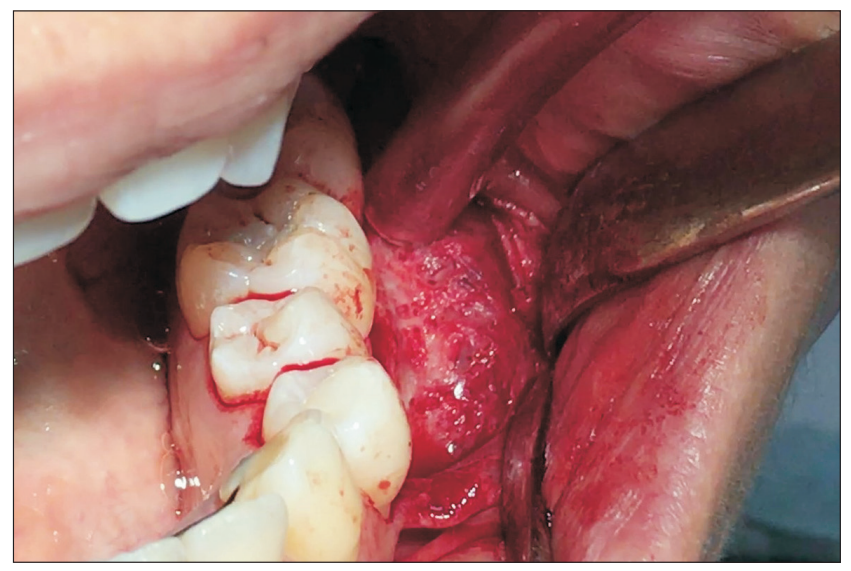

Fig. 6. Intraoperative image after flap raising.

Maria Isabel Sánchez Jorge et al: Diagnostic challenge and management of intraosseous mandibular hemangiomas: a case report and literature review. J Korean Assoc Oral Maxillofac Surg 2021

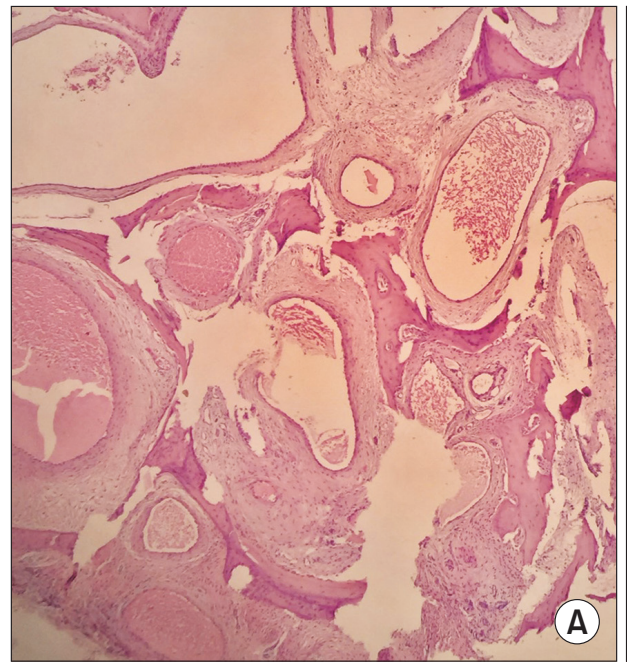

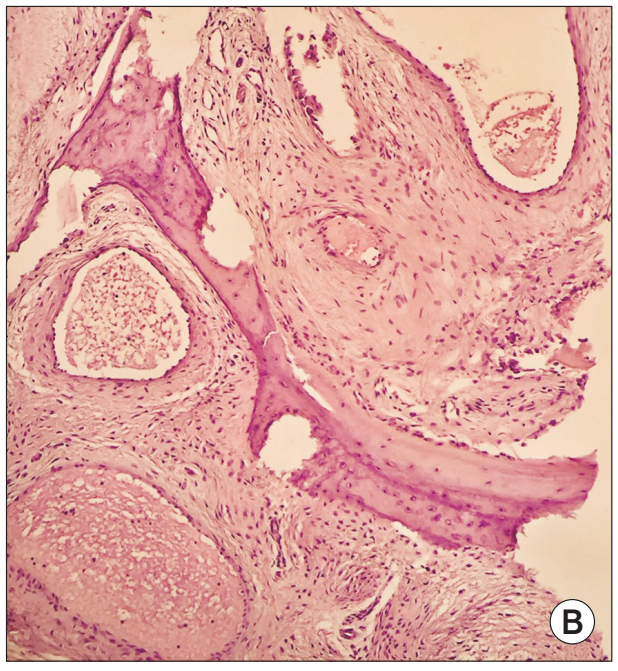

Fig. 5. Histologic study. H\&E-stained specimen $(\mathrm{A}: \times 10, \mathrm{~B}: \times 20)$ showing the presence of bone trabeculae and spicules between numerous vascular structures with muscular walls and dilated spaces separated from one another by fibrous tissue.

Maria Isabel Sánchez Jorge et al: Diagnostic challenge and management of intraosseous mandibular hemangiomas: a case report and literature review. $J$ Korean Assoc Oral Maxillofac Surg 2021 


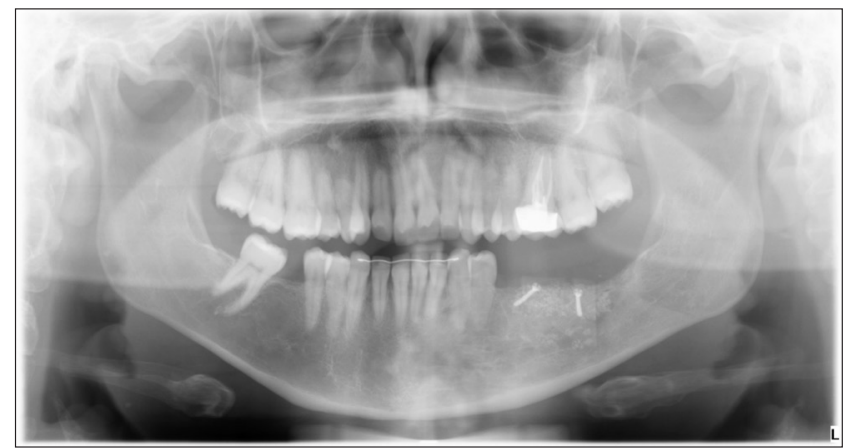

Fig. 7. Panoramic radiograph after ramus graft showing no signs of relapse.

Maria Isabel Sánchez Jorge et al: Diagnostic challenge and management of intraosseous mandibular hemangiomas: a case report and literature review. J Korean Assoc Oral Maxillofac Surg 2021

skull; hemangioma is extremely rare in the jaw. Regarding jawbone hemangioma, most researchers agree that there is a higher incidence in the mandible than in the maxilla ${ }^{6-9}$. In an investigation by Donohue et al. ${ }^{1}$, two-thirds of jaw hemangioma presented in the mandible and one-third in the maxilla, and they tended to show a special predilection for the mandibular premolar and molar regions (as the present case substantiates), followed by the ascending ramus, condyle, and palate $^{1,8,10}$.

Based on their appearance under the microscope, hemangioma can be classified into three types: cavernous, capillary, and mixed. Cavernous hemangiomas show large vascular spaces with little fibrous tissue stroma, while the vascular spaces are small, and stroma is abundant in the capillary type. The mixed type shows features of both the other types ${ }^{3,4}$. Capillary hemangioma, characterized by the presence of tiny, fine blood vessels, is usually present at birth, affecting soft tissue, and usually decreases in size during the post-natal phase. Most cavernous hemangioma appears in adulthood and represents the majority of intraosseous hemangiomas in the maxillofacial massif ${ }^{2}$, as in the present case. Nevertheless, although rare, a few cases of capillary intraosseous hemangioma have been reported, for example, by Dereci et al. ${ }^{11}$.

Intraosseous hemangiomas are also classified in terms of their site of origin as peripheral or central hemangiomas. The peripheral type originates in periosteum blood vessels with a growth pattern towards medullar bone, while the central type originates in medullar bone and extends towards cortical bone $e^{4,5}$.

The origin of intraosseous hemangiomas is a subject of debate. They have been regarded as real neoplasias, in which the dental artery of the lower dental canal is the origin of the lesion, which would explain its greater predilection for man- dibular premolar and molar regions ${ }^{1}$ in addition to why the canal is widened in many of these cases ${ }^{5}$.

Other authors consider them to be hamartomas, the result of intraosseous mesoderm cell proliferation that undergoes endothelial differentiation ${ }^{1,4,5,10}$.

Intraosseous hemangiomas have also been considered congenital lesions originating in the bone medulla, as remains of active hematopoietic medulla have been detected in posterior areas of the mandible, the areas where hemangiomas most often occur ${ }^{1}$.

Their pathogenesis remains unknown. Some authors note localized trauma as a possible cause as it is not uncommon for hemangioma patients to present antecedents of trauma ${ }^{2,3}$.

Intraosseous hemangiomas grow very slowly and remain clinically indiscernible until they reach a size noticeable by the patient, usually as a swelling of generally hard consistency, as in the present case. Nevertheless, cases of hemangioma of soft consistency have been described ${ }^{12}$. At times they may be accompanied by pain, as in the case reported by Dhiman et al. ${ }^{10}$; speech difficulties, as reported by Elif et al. ${ }^{2}$; reduced mouth opening, as mentioned by Donohue et al. ${ }^{1}$; a throbbing sensation, bleeding in the gingival sulcus, and a reddish coloration, as reported by Fernández et al. ${ }^{8}$; paresthesia, as in the case described by Eliot and Castle ${ }^{13}$; root resorption ${ }^{4,8-10}$; dental mobility; and dental exfoliation ${ }^{1,3,4}$. Reports even include a case of retention of an upper canine and its displacement towards the zygomatic bone, probably provoked by the presence of an intraosseous hemangioma ${ }^{14}$. The relevance of hemangioma lies in its proximity to dental structures, involving a high risk of hemorrhage when a dental extraction is performed.

In addition to the enduring absence of clinical manifestations, their radiographic appearance is not pathognomonic and may be very similar to a range of other bone lesions, making diagnosis complicated. Vascular anomalies are known to be of very similar appearance radiographically ${ }^{1}$. The absence of clinical signs in the present case meant that the lesion went unnoticed for several years, although an earlier panoramic radiograph showed an altered bone pattern.

Among the possible radiographic manifestations of intraosseous hemangioma, the most characteristic is a honeycomb pattern in panoramic radiographs, an image that, according to Sepulveda et al. ${ }^{4}$, appears in $50 \%$ of cases. A sunburst image characteristically appears in CT scans due to the presence of reactive bone spicules ${ }^{1,2}$. Both types of images appeared in the panoramic radiograph and CT captured in the present case. However, these images do not always appear, and hem- 
angioma often appears as just a unilocular ${ }^{1,9}$ or multilocular ${ }^{12}$ radiolucent image similar to cystic lesions. Cases of radiopaque appearance have also been described ${ }^{2,9}$.

Sometimes, the lower dental canal appears wider than usual, suggesting the vascular origin of the lesion ${ }^{5,6,12}$.

When making a diagnosis, osteomas, giant cell tumor, fibrous dysplasia, dermoid tumor, chondrosarcoma, osteogenic sarcoma, dental cyst, aneurysmal or solitary bone cyst, ameloblastoma, and myxoma are among the entities that must be included in differential diagnosis ${ }^{1,2,5,13,15,16}$. Certain diagnoses can only be obtained by biopsy, which should be performed with caution due to the high risk of hemorrhage; fine-needle aspiration biopsy reduces this risk ${ }^{1}$.

Deciding on the most effective treatment should be determined by the tumor's location, size, and blood supply ${ }^{3,6}$. Among the recommended radiographic tests are panoramic radiographs, computed axial tomography (CAT) scans, nuclear magnetic resonance (NMR), and conventional angiography ${ }^{2,3}$. The CAT scan is considered the most useful imaging technique for assessing details relating to trabecular and cortical bone ${ }^{2}$. NMR is the most effective method for identifying the depth and extent of the lesion in soft tissues ${ }^{1,2}$, as well as its blood flow ${ }^{5}$. The injection of a contrast medium in both CAT and NMR makes it possible to assess cortical involvement and the extent of the lesion ${ }^{4}$. Angiography imparts visualization of the main vessels supplying the lesion ${ }^{3}$.

The ideal choice of treatment must consider the patient's age; medical state; and the tumor's clinical manifestations, size, extent, and blood supply into account.

Most authors agree that the most effective treatment for preventing recurrence is complete resection of the tumor ${ }^{2,10}$, recommending block excision of the lesion including a safety margin of surrounding healthy bone and nutrient vessel ligation if present. In most cases, surgical excision of the lesion will require reconstruction of the eliminated area. To do this, the use of titanium plates is proposed, which may be combined with grafts harvested from the ribs, iliac crest, or other bone sites $^{10,12,17}$.

As alternatives to complete tumor resection, other treatments have been proposed, such as radiotherapy, sclerotherapy, embolization, and ligation of the external carotid artery ${ }^{2-4}$.

Today, radiotherapy is reserved for cases in which surgery is not a viable option because of potential adverse effects, such as telangiectasia, delayed bone and dental growth, tissue necrosis, or malignant degeneration ${ }^{12}$.

Sclerotherapy is not considered effective because of the lesion's bone affectation ${ }^{12}$ and could be dangerous in any case due to the proximity to intracranial circulation ${ }^{3}$.

The use of isolated embolization has been described as successful in the treatment of intraosseous hemangioma in a case report by Sepulveda et al. ${ }^{4}$, but its efficacy is only palliative in many cases. Embolization is more commonly used preoperatively to reduce the risk of hemorrhage during surgery ${ }^{1}$. Although many authors consider this unnecessary, providing excision should include adequate safety margins ${ }^{2}$, as in the case described here. It is also important to take into account that embolization may be subject to complications, including atheroma release, catheter breakage, vessel breakage, hemiplegia, blindness, facial paralysis, allergic reactions, and avascular necrosis of the mandible ${ }^{6}$.

External carotid artery ligation is not an effective treatment either, as the formation of collateral circulation derived from the collateral external carotid artery or the ipsilateral internal carotid artery does not result in the loss of tumor vasculariza$\operatorname{tion}^{3,6}$.

Clinical observation of intraosseous hemangioma is only indicated for asymptomatic patients with minimal or no facial deformity $^{1,4,5}$.

Malignant transformation of intraosseous hemangioma is extremely rare and has only been reported following radiotherapy ${ }^{1}$.

Generally, the prognosis of intraosseous hemangioma is good once the lesion has been removed and bone regeneration is underway ${ }^{3}$. However, although uncommon, relapses have been reported ${ }^{2,9}$.

Intraosseous hemangioma of the mandible is a rare benign bone tumor. The difficulty of diagnosing this lesion is due to not only its low incidence but also to its multiple and nonspecific forms of clinical and radiographic presentation. Early diagnosis is important because even though benign, early treatment is advised to avoid major complications derived from local growth, which can worsen prognosis.

\section{ORCID}

Maria Isabel Sánchez Jorge, https://orcid.org/0000-0001$5820-766 X$

Jorge Cortés-Bretón Brinkmann, https://orcid.org/00000003-1701-8867

Aranzazu González Corchón, https://orcid.org/0000-0002$1192-2233$

Rosa Acevedo Ocaña, https://orcid.org/0000-0002-5234-9402 


\section{Authors' Contributions}

A.G.C. operated the case and helped in crafting the study design. M.I.S.J. and J.C.B.B. participated in study design and coordination and helped to draft the manuscript. R.A.O. contributed to the study design and wrote the manuscript. All authors contributed to data acquisition and analysis, and they also read and approved the final manuscript.

\section{Conflict of Interest}

No potential conflict of interest relevant to this article was reported.

\section{References}

1. Donohue CA, de la Torre MA, de la Torre MG, Sánchez AJG, López MJA, Guzmán GDA, et al. Hemangioma intraóseo: reto diagnóstico. Presentación de un caso y revisión de la literatura. Rev ADM 2016;73:39-43. Spanish.

2. Elif B, Derya Y, Gulperi K, Sevgi B. Intraosseous cavernous hemangioma in the mandible: a case report. J Clin Exp Dent 2017:9:e153-6. https://doi.org/10.4317/jced.52864

3. Treviño AMG, Valdés MJ, Martínez MHR, Moreno TMG, Rivera SG. Hemangioma intraóseo de la mandíbula. Reporte de un caso clínico. Rev ADM 2016;73:96-8. Spanish.

4. Sepulveda I, Spencer ML, Platin E, Trujillo I, Novoa S, Ulloa D. Intraosseous hemangioma of the mandible: case report and review of the literature. Int J Odontostomat 2013;7:395-400. https://doi. org/10.4067/S0718-381X2013000300010

5. Gómez Oliveira G, García-Rozado A, Luaces Rey R. Intraosseous mandibular hemangioma. A case report and review of the literature. Med Oral Patol Oral Cir Bucal 2008;13:E496-8.

6. Luaces Rey R, García-Rozado González A, López-Cedrún Cembranos L, Ferreras Granado J, Charro Huerga E. Intraosseous hemangioma of the mandible. An intraoral approach. Rev Esp Cirug Oral y Maxilofa 2006;28:195-9.

7. Zlotogorski A, Buchner A, Kaffe I, Schwartz-Arad D. Radiological features of central haemangioma of the jaws. Dentomaxillofac Radiol 2005;34:292-6. https://doi.org/10.1259/dmfr/37705042
8. Fernández LR, Luberti RF, Domínguez FV. Radiographic features of osseous hemangioma in the maxillo-facial region. Bibliographic review and case report. Med Oral 2003;8:166-77.

9. Chandra SR, Chen E, Cousin T, Oda D. A case series of intraosseous hemangioma of the jaws: various presentations of a rare entity. J Clin Exp Dent 2017;9:e1366-70. https://doi.org/10.4317/ jced. 54285

10. Dhiman NK, Jaiswara C, Kumar N, Patne SC, Pandey A, Verma V. Central cavernous hemangioma of mandible: case report and review of literature. Natl J Maxillofac Surg 2015;6:209-13. https:// doi.org/10.4103/0975-5950.183866

11. Dereci O, Acikalin MF, Ay S. Unusual intraosseous capillary hemangioma of the mandible. Eur J Dent 2015;9:438-41. https://doi. org/10.4103/1305-7456.163236

12. Chetan BI, Sharmila, Shruthi DK, Karthik B. Diagnostic and surgical aspects of central hemangioma of mandible: a surgical approach for the reconstruction of mandible. J Int Oral Health 2015;7:56-8.

13. Eliot CA, Castle JT. Intraosseous hemangioma of the anterior mandible. Head Neck Pathol 2010;4:123-5. https://doi.org/10.1007/ s12105-010-0170-x

14. Kalsi H, Scannell J. Unusual presentation of an intraosseous hemangioma of the maxilla and displaced canine. Int $\mathrm{J}$ Clin Pediatr Dent 2013;6:124-6. https://doi.org/10.5005/jp-journals-10005-1203

15. Kaya B, Işılgan SE, Cerkez C, Otrakçı V, Serel S. Intraosseous cavernous hemangioma: a rare presentation in maxilla. Eplasty 2014;14:e35.

16. Handa H, Naidu GS, Dara BG, Deshpande A, Raghavendra R. Diverse imaging characteristics of a mandibular intraosseous vascular lesion. Imaging Sci Dent 2014;44:67-73. https://doi.org/10.5624/ isd.2014.44.1.67

17. Omeje K, Efunkoya A, Amole I, Akhiwu B, Osunde D. A twoyear audit of non-vascularized iliac crest bone graft for mandibular reconstruction: technique, experience and challenges. J Korean Assoc Oral Maxillofac Surg 2014;40:272-7. https://doi.org/10.5125/ jkaoms.2014.40.6.272

How to cite this article: Sánchez Jorge MI, Cortés-Bretón Brinkmann J, González Corchón A, Acevedo Ocaña R. Diagnostic challenge and management of intraosseous mandibular hemangiomas: a case report and literature review. J Korean Assoc Oral Maxillofac Surg 2021;47:321-326. https://doi.org/10.5125/jkaoms.2021.47.4.321 